\title{
APPLICATION OF ANN FOR ULTIMATE SHEAR STRENGTH OF FLY ASH CONCRETE BEAMS
}

\author{
Putte Gowda B.S ${ }^{1}$, Aswath M.U' ${ }^{2}$, Muthu K.U ${ }^{3}$, Udaya B.N ${ }^{4}$ \\ ${ }^{1}$ Assitant Professor, ${ }^{2}$ Professor, Dept. of Civil Engineering, BIT, Bangalore-560004 \\ ${ }^{3}$ Professor, Brindavan College of Engineering, Bangalore \\ ${ }^{4}$ Post Graduate Scholar, Department of Civil Engineering, MIT, Manipal, Udupi \\ puttuji123@gmail.com,aswathmu@yahoo.com,kumuthu64@gmail.com, udistructures21@gmail.com
}

\begin{abstract}
The application of artificial neural networks (ANN) for ultimate shear strength of fly ash concrete beams with transverse reinforcement is investigated in this paper. An ANN model is built, trained and tested using the available test data of 216 RC beams collected from the literature also the experimental data of twenty seven fly ash concrete beams under shear. The experimental shear strength were also compared to those obtained using building codal equations and empirical equations proposed by various researchers. The ANN model was found to predict satisfactorily when compared to available analytical predictions.
\end{abstract}

Keywords: Artificial Neural Network (ANN), Building codes, Comparison, Charts, Empirical Equations, Fly ash Concrete, Shear Strength.

\section{INTRODUCTION}

Artificial neural networks are, by definition, interconnected networks of processing elements that have the ability to be trained to map a given input into the desired output. ANN's possess some distinctive properties not found in conventional computational models. In most cases however, there are only observational data of the problem, while the underlying rules relating the input variables to the output variables are either unknown or extremely difficult to discover. Under these circumstances, ANN's exhibit their superiorities over conventional computational techniques. ANN's are composed of many interconnected processing units. Each processing unit keeps some information locally, is able to perform some simple computations, and can have many inputs but can send only one output. The ANN's have the capability to respond to input stimuli and produce the corresponding response, and to adapt to the changing environment by learning from experience. Therefore, in order for researchers to use ANN's as a predictive tool, data must be used to train and test the model to check its successfulness.

The manner in which the neural elements (neurons, layers, biases, etc.,) are connected determines the network architecture and the number of neurons and layers determines the network size. Sometimes there is also a constant value, or bias, that is added to the input signals. The unit then calculates the net input, which is a weighted sum of its inputs plus the bias value:

$$
n e t_{i}=\sum_{+b_{i} \ldots \ldots} w_{i j} A_{j}
$$

\section{NEURAL NETWORK MODEL}

In this study, a computer programmed tool was used to develop an ANN model for predicting the ultimate shear strength of fly ash concrete beams. The program requires the following input data:

- The total number of data that is presented (in this case, $216 \mathrm{RC}$ beams +27 fly ash concrete beams were considered) under shear. The computer program uses $68.14 \%$ of the data for training, $15.93 \%$ for validation and $15.93 \%$ for testing.

- The number of input neurons (9 in this study) and the output neurons ( 1 in this study).

- In the current analysis a Levenberg-Marquardt[12] learning algorithm, an approximation to Newton's method more is used. The LM algorithm is efficient in terms of high speed of convergence and reduced memory requirements compared to the two previous methods. In general, with networks that contain up to several hundred weights, the LM algorithm has the fastest convergence.

- To determine the best performance network a trial and error search procedure was employed to determine the number of hidden layers in the network.

- For a given architecture and a fixed number of iterations say 500, the number of hidden layers was altered and the network which provides the least error (test data) is selected. 
Table 1- The following nine variables are used as input parameters:

\begin{tabular}{|c|l|c|c|c|c|c|c|c|c|}
\hline $\begin{array}{c}\text { Input } \\
\text { parameters }\end{array}$ & $\begin{array}{l}\mathbf{B} \\
(\mathbf{m m})\end{array}$ & $\begin{array}{c}\mathbf{D} \\
(\mathbf{m m})\end{array}$ & $\mathbf{a} / \mathbf{d}$ & $\begin{array}{c}\mathbf{f}_{\mathbf{c}}^{\prime} \\
(\mathbf{M P a})\end{array}$ & $\begin{array}{c}\boldsymbol{\rho} \\
(\boldsymbol{\%})\end{array}$ & $\begin{array}{c}\boldsymbol{\rho}_{\mathbf{v}} \\
(\boldsymbol{\%})\end{array}$ & $\begin{array}{c}\mathbf{f}_{\mathbf{y}} \\
(\mathbf{M p a})\end{array}$ & $\begin{array}{c}\mathbf{f}_{\mathbf{v y}} \\
(\mathbf{M p a})\end{array}$ & $\begin{array}{c}\mathbf{d}_{\mathbf{a}} \\
(\mathbf{m m})\end{array}$ \\
\hline $\begin{array}{c}\text { Range } \\
(\text { min-max })\end{array}$ & $64-356$ & $140-575$ & $1.1-2.5$ & $13.79-120$ & $0.16-$ & $\begin{array}{c}0.074- \\
2.7\end{array}$ & $\begin{array}{c}320.6- \\
931\end{array}$ & $250-1238$ & $7-25$ \\
\hline
\end{tabular}

\section{NETWORK TRAINING ANALYSIS}

In the present work, the best architecture was 9-17-1 i.e. 9 inputs, 17 hidden layers and 1 output. The data of the 243 beams are grouped randomly into training, validating and testing set before presenting them to the network for analysis.

\section{EXPERIMENTAL WORK ON FLY ASH}

\section{CONCRETE BEAMS}

To understand the behavior of fly ash concrete beams two cement replacement levels by fly ash are considered viz. $20 \%$ and $35 \%$.Mix design of normal concrete (without fly ash) of grade M40 was obtained as per IS method as outlined in IS: 10262-1982.Mix proportion that arrived at for normal concrete itself was adopted for fly ash concrete, with only change in certain replacement of cement by fly ash (i.e $20 \%$ to $35 \%$ ).

Table: 2 -Mix Proportions for Normal Concrete

\begin{tabular}{|c|c|c|c|c|}
\hline $\begin{array}{c}\text { Cement } \\
\mathrm{Kg} / \mathrm{m}^{3}\end{array}$ & $\begin{array}{c}\text { Water } \\
\mathrm{Kg} / \mathrm{m}^{3}\end{array}$ & $\begin{array}{c}\text { Fine Aggregates } \\
\mathrm{Kg} / \mathrm{m}^{3}\end{array}$ & $\begin{array}{c}\text { Coarse Aggregates } \\
\mathrm{Kg} / \mathrm{m}^{3}\end{array}$ & $\begin{array}{c}\text { Water/Cement ratio } \\
\mathrm{Kg} / \mathrm{m}^{3}\end{array}$ \\
\hline 385 & 140 & 862 & 1097 & 0.364 \\
\hline
\end{tabular}

Table.3 -Details of the tested beams with Failure loads

\begin{tabular}{|c|c|c|c|c|c|c|c|c|c|}
\hline $\mathbf{B}$ & $\mathbf{D}$ & $\mathbf{a} / \mathbf{d}$ & $\begin{array}{c}\mathbf{f}_{\mathbf{c}} \\
(\mathbf{m m})\end{array}$ & $\begin{array}{c}\mathbf{P} \\
(\mathbf{M m})\end{array}$ & $\begin{array}{c}\mathbf{\rho}_{\mathbf{v}} \\
(\mathbf{\%})\end{array}$ & $\begin{array}{c}\mathbf{f}_{\mathbf{y}} \\
(\mathbf{\%})\end{array}$ & $\begin{array}{c}\mathbf{f}_{\mathbf{v y}} \\
(\mathbf{M p a})\end{array}$ & $\begin{array}{c}\mathbf{d}_{\mathbf{a}} \\
(\mathbf{m m})\end{array}$ & $\begin{array}{c}\mathbf{E X P} \mathbf{V}_{\mathbf{u}} \\
(\mathbf{K N})\end{array}$ \\
\hline 125 & 225 & 1.77 & 50.90 & 0.91 & 0.53 & 415 & 415 & 12 & 130 \\
\hline 125 & 225 & 1.77 & 68.30 & 1.60 & 0.53 & 415 & 415 & 12 & 200 \\
\hline 125 & 225 & 1.77 & 64.00 & 2.23 & 0.53 & 415 & 415 & 12 & 230 \\
\hline 125 & 225 & 1.77 & 60.75 & 0.91 & 0.40 & 415 & 415 & 12 & 146 \\
\hline 125 & 225 & 1.77 & 61.04 & 1.60 & 0.40 & 415 & 415 & 12 & 190 \\
\hline 125 & 225 & 1.77 & 57.40 & 2.23 & 0.40 & 415 & 415 & 12 & 260 \\
\hline 125 & 225 & 1.77 & 53.41 & 0.91 & 0.53 & 415 & 415 & 12 & 130 \\
\hline 125 & 225 & 1.77 & 55.08 & 1.60 & 0.53 & 415 & 415 & 12 & 210 \\
\hline 125 & 225 & 1.77 & 56.68 & 2.23 & 0.53 & 415 & 415 & 12 & 250 \\
\hline 125 & 225 & 1.77 & 54.64 & 0.91 & 0.40 & 415 & 415 & 12 & 140 \\
\hline 125 & 225 & 1.77 & 51.60 & 1.60 & 0.40 & 415 & 415 & 12 & 220 \\
\hline 125 & 225 & 1.77 & 50.14 & 2.23 & 0.40 & 415 & 415 & 12 & 240 \\
\hline 125 & 225 & 1.77 & 51.30 & 0.91 & 0.34 & 415 & 415 & 12 & 138 \\
\hline 125 & 225 & 1.77 & 52.32 & 1.60 & 0.34 & 415 & 415 & 12 & 180 \\
\hline 125 & 225 & 1.77 & 50.00 & 2.23 & 0.34 & 415 & 415 & 12 & 270 \\
\hline 125 & 225 & 1.77 & 65.40 & 0.91 & 0.34 & 415 & 415 & 12 & 140 \\
\hline
\end{tabular}




\begin{tabular}{|l|l|l|l|l|l|l|l|l|l|}
\hline 125 & 225 & 1.77 & 68.30 & 1.60 & 0.34 & 415 & 415 & 12 & 228 \\
\hline 125 & 225 & 1.77 & 66.53 & 2.23 & 0.34 & 415 & 415 & 12 & 250 \\
\hline 125 & 225 & 1.77 & 58.86 & 0.91 & 0.53 & 415 & 415 & 12 & 140 \\
\hline 125 & 225 & 1.77 & 60.70 & 1.60 & 0.53 & 415 & 415 & 12 & 220 \\
\hline 125 & 225 & 1.77 & 58.42 & 2.23 & 0.53 & 415 & 415 & 12 & 240 \\
\hline 125 & 225 & 1.77 & 55.51 & 0.91 & 0.40 & 415 & 415 & 12 & 138 \\
\hline 125 & 225 & 1.77 & 52.84 & 1.60 & 0.40 & 415 & 415 & 12 & 180 \\
\hline 125 & 225 & 1.77 & 51.68 & 2.23 & 0.40 & 415 & 415 & 12 & 270 \\
\hline 125 & 225 & 1.77 & 52.25 & 0.91 & 0.34 & 415 & 415 & 12 & 140 \\
\hline 125 & 225 & 1.77 & 60.00 & 1.60 & 0.34 & 415 & 415 & 12 & 228 \\
\hline 125 & 225 & 1.77 & 66.45 & 2.23 & 0.34 & 415 & 415 & 12 & 250 \\
\hline
\end{tabular}

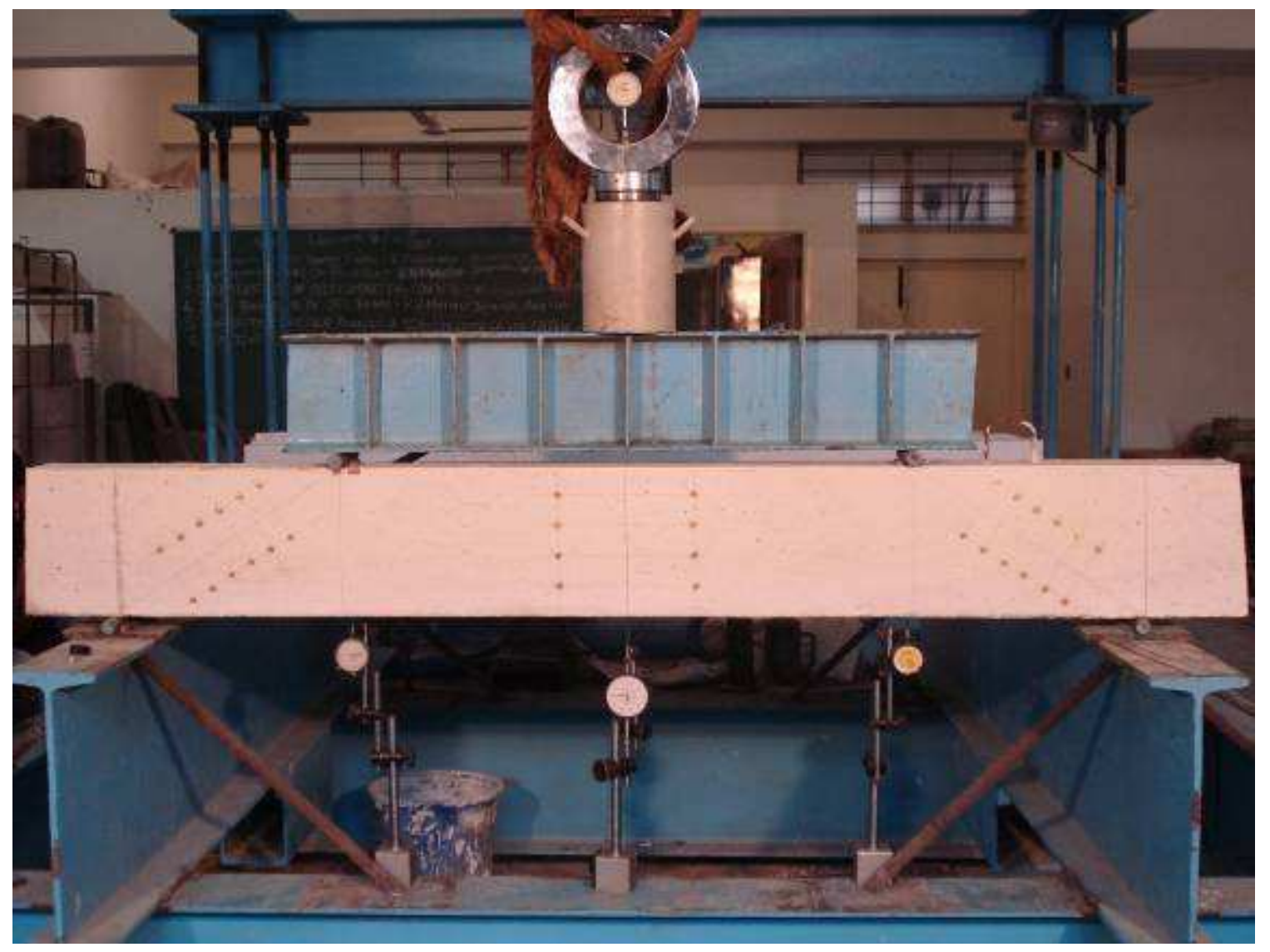

Fig: 1 Test Setup

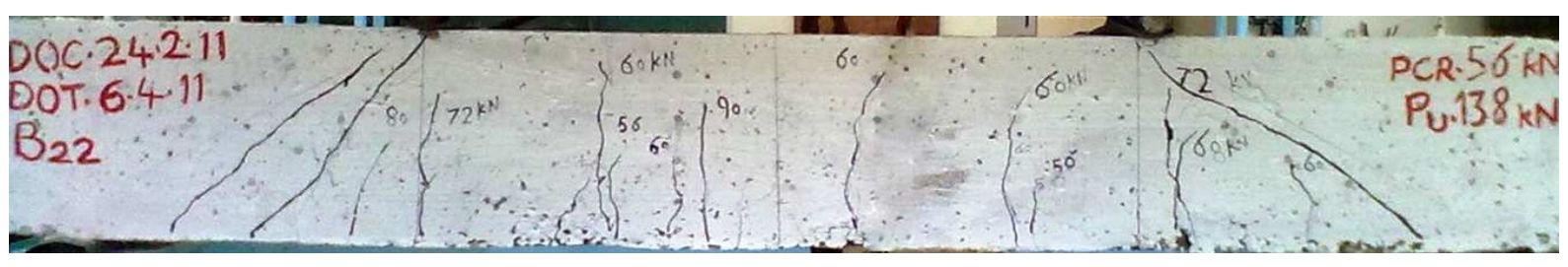

Fig.2 Crack Pattern of Fly ash Concrete Beam 


\section{THEORETICAL COMPUTATION OF}

\section{ULTIMATE SHEAR STRENGTH}

Ultimate Shear strength was computed using various codes of practices and various other researchers as listed below:

Codal Equations

ACI 318-12

CSA A23.3-94

Euro code EN 1992-1-1

German code DIN 1045-1

Japanese Code

CEB-FIP model code

\section{Researchers Equation}

Zsutty (1971)

Bazant and Kim (1984)

Kim and Park (1996)

Rebeiz (1999)

Collins and Kuchma (1999)

Sarkar et al. (1999)
British Standards BS-8110

New Zealand Code NZS

Australian Code, AS 3600

Norwegian Code, NS 3473E

Indian Code of practice

\section{RESULTS AND COMPARISIONS}

The Ultimate Shear strength has been calculated by using the available analytical model and shear strength was predicted. The comparison between the predicted and the experimental data is shown in Fig 3 to Fig 24.

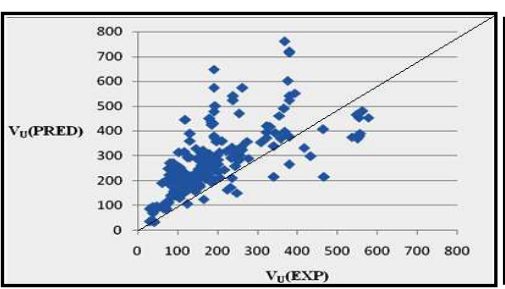

Fig. 3 ACI

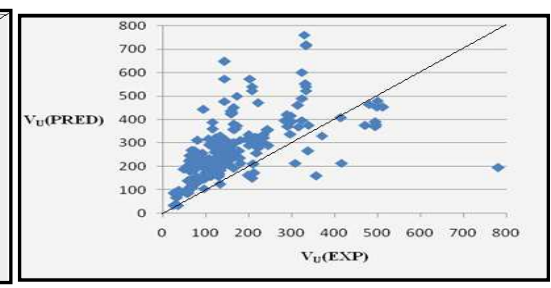

Fig.4 CSA

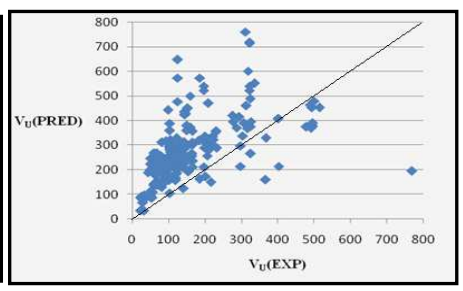

Fig.5 EURO
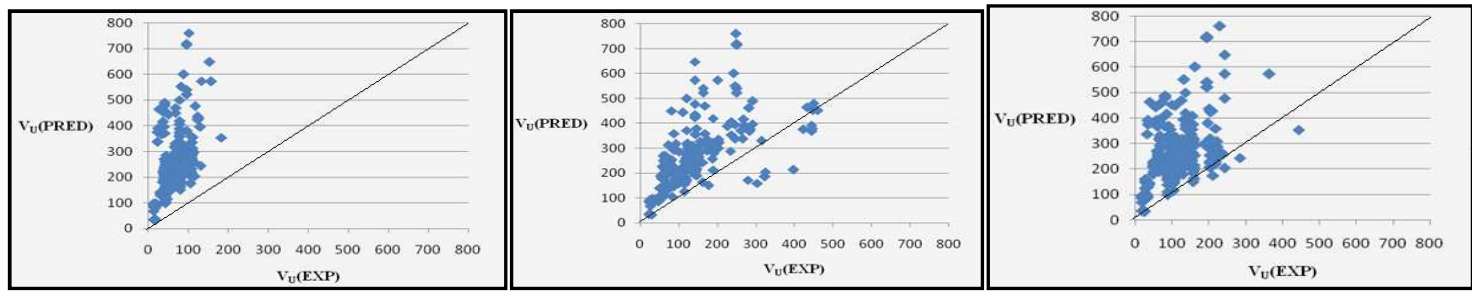

Fig.6 GERMAN

Fig.7 BRITISH

Fig.8 CEB-FIP

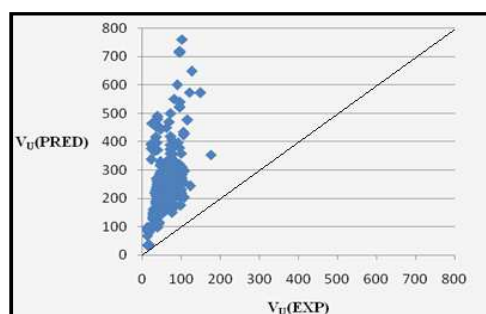

Fig.9 JAPANESE

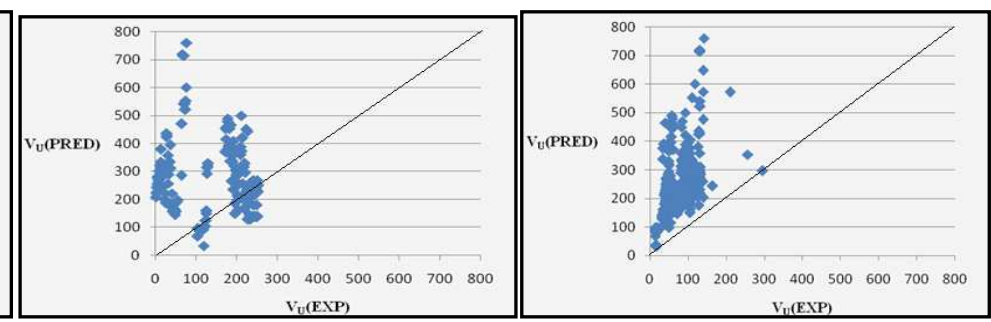

Fig.10 NEWZEALAND

Fig.11 NORWEGIAN

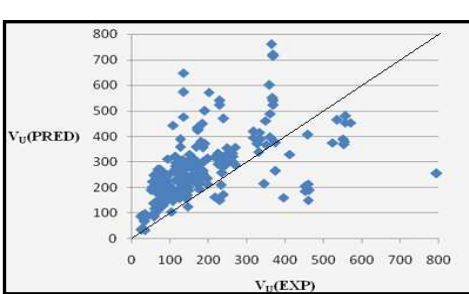

Fig.12 INDIAN

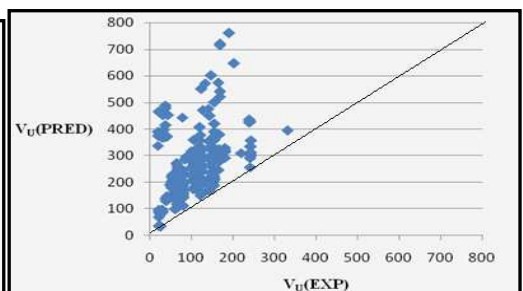

Fig.13 BAZANT

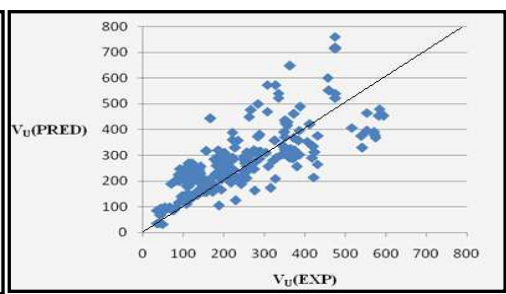

Fig.14 ZSUTTY 


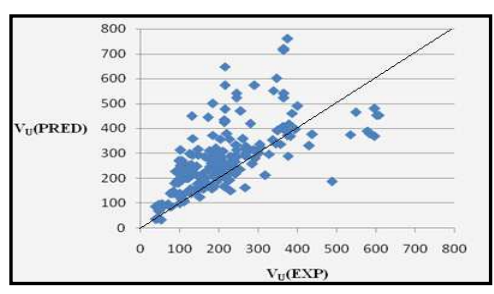

Fig.15 CLADERA

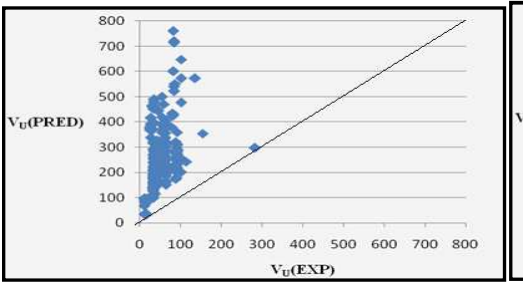

Fig.16 COLLINS

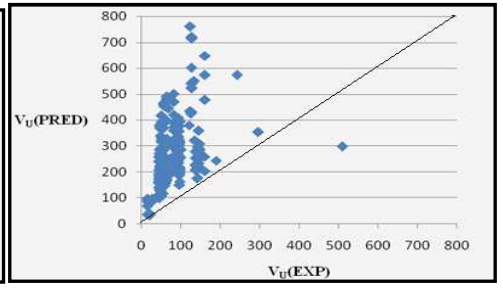

Fig.17 DESAI

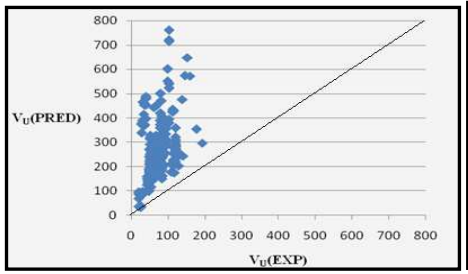

Fig.18 GASTEBLED

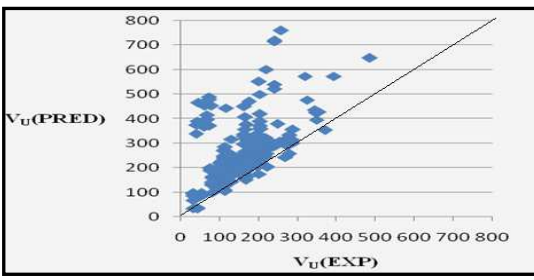

Fig.19 KIM \& PARK

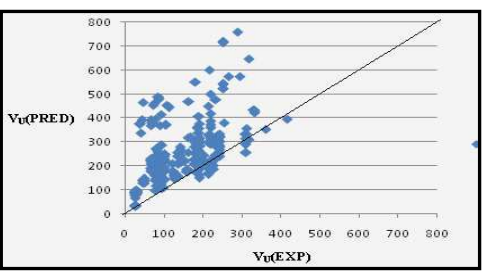

Fig.20 KIM et al

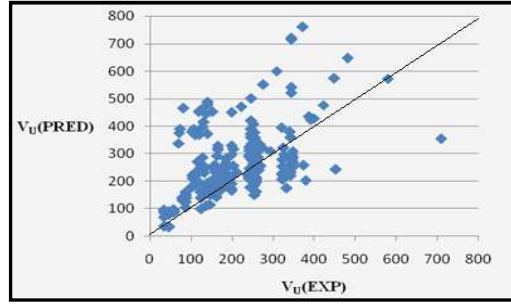

Fig.21 REBIZ

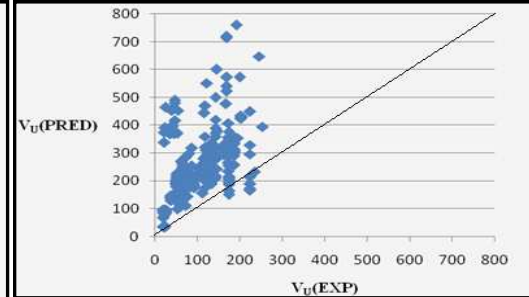

Fig.22 RUSSO

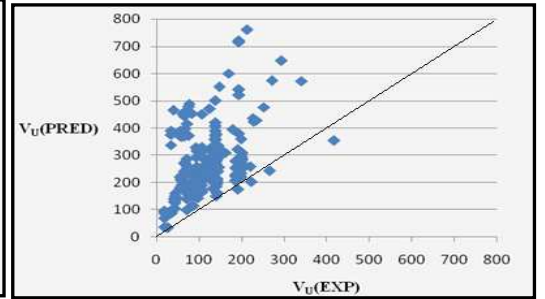

Fig.23 SARKAR

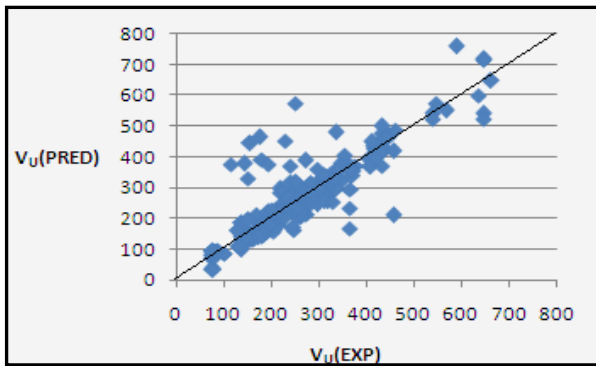

Fig.24 ANN

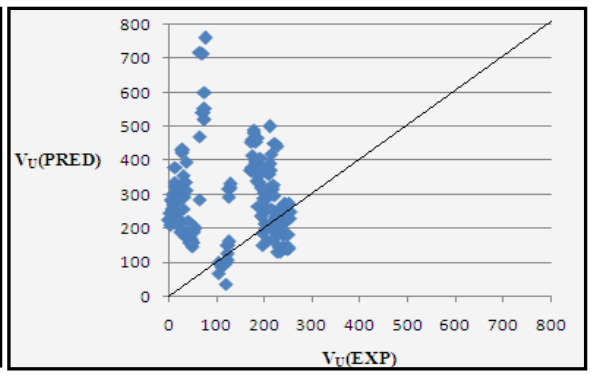

Fig.25 AUSTRALIAN
The comparison showed that the codal equations are not able to predict the experimental ultimate shear strength satisfactorily however the equation proposed by Zsutty [Fig.14] is able to predict the ultimate shear strength when compared to the other available methods.

Also the results of ANN [Fig.24] show a better prediction when compared to codal and empirical prediction, considering all the 10 equations and the codal provisions it is found that Zsutty results are found to be better than others.

\section{SUMMARY AND CONCLUSIONS}

An experimental program has been design to cast and test 27 fly ash concrete beams under shear. The shear strength of the tested beam were computed by using the available theoretical models, as a wide variation was observed for the predictions of ultimate shear strength of the tested beams and a attempt has made to apply the soft computing tool that is ANN. A large database of conventional reinforced concrete beams tested under shear as been used as an input to the ANN. It has found that ANN is able to predict satisfactorily the ultimate shear strength of conventionally reinforced concrete beams. 
As no theoretical model is available exclusively for fly ash Concrete beams an attempt has been made to apply ANN which has been validated to fly ash beams.

- For the network model 9-17-1 used to predicting the shear strengths of fly ash concrete beams, the average of ratio of predicted value to experimental value of shear strength was 1.02 with Coefficient Of Variation (COV) of 0.3 .

- For beams with shear reinforcement Zsutty's equation provided the least $\mathrm{COV}=0.05$ and the ratio of predicted strength to experimental shear strength is 0.875 .

Thus the Zsutty's prediction is better than the available close form solutions. The present investigation highlights an alternative method which is simply to apply ANN for the prediction of shear strength of GPC beams.

\section{REFERENCES}

[1] ACI 318R-02, Building code requirements for Structural Concrete (ACI 318-02) and commentary (ACI 318R-02), American Concrete Institute.

[2] Eurocode-2, Design of concrete structures, European committee for standardization, Brussels 1999.

[3] NZS 95, Standards New Zealand, Design of concrete structures, NZS 3101 1995, Wellington, New Zealand.

[4] CEB-FIP 1990, CEB FIP Model Code, 'Comite' Euro International du Beton (CEB), Thomas Telford London.

[5] AS 3600, Concrete Structures, Standards Australia, Home burls, NSW, Australia, 1994.

[6] IS 456-2000 "Plain and Reinforced Concrete -Code of practice ", fourth revision, Bureau of Indian standards, New Delhi.

[7] Theodore Zsutty (1968), "Beam Shear Strength prediction by analysis of existing data ", ACI Structural Journal, v 65, No.11, November 1968, pp.943-951

[8] Theodore Zsutty (1971), "Shear Strength Prediction for separate Categories of simple Beam Tests", ACI Structural Journal, V 68, No 2, Feb-Mar 1971, pp.138143

[9] Robert J. Frosch (2000). "Behavior of Large -Scale Reinforced Concrete Beams with Minimum Shear Reinforcement", ACI Structural Journal, V 97, No.6, Nov-Dec 2000, pp 814-820.

[10] Raghu S. Pendyala and Priyan Mendis (2000). "Experimental Study on Shear Strength of High Strength Concrete Beams", ACI Structural Journal, V 97, No.4, Jul-Aug 2000, pp 564-571.

[11] Putte Gowda B.S, Aswath M.U and Muthu K.U. "Experimental Investigation on Shear Behaviour of Fly Ash Concrete Beams", International Journal of Emerging Trends in Engineering and Development. Vol 2, No 4. pp 573-586.

[12] J.J More, (1977) "The Levenberg-Marquardt algorithm: Implementation Theory in Numerical Analysis",
Lecture Notes in Mathematics, (G.A Watson) ed., New York, USA: Springer Verlag, V. 630, pp. 105-116, 1977. 